\title{
José del Perojo y la "cuestión cubana": la última fase del colonialismo político y económico español en América
}

Fernando Hermida de Blas

Universidad Autónoma de Madrid

Resumen

En este texto se reconstruye, en primer lugar, la biografía intelectual de José del Perojo, introductor en España del primer movimiento neokantiano ("Primera Escuela de Madrid"); en segundo lugar, se analiza la relación establecida en el pensamiento de Perojo entre el neokantismo, el darwinismo social y la teoría de los partidos políticos; en tercer lugar, se explica cómo Perojo aplica a la "cuestión cubana" su pensamiento en torno a los tres ejes citados.

Palabras clave: José del Perojo, neokantismo, darwinismo social, política, economía, monismo, colonialismo, "cuestión cubana"

\section{Abstract}

Firstly, we study José del Perojo 's intellectual biography, who introduced in Spain the First Neokantism ("Primera Escuela de Madrid"); secondly, we analyze the relation that is established in Perojo's thought between the Neokantism, the Social Darwinism, and the theory of the political parties; thirdly, is explained how Perojo applies to the "cuestion cubana" his thought concerning the three mentioned axes. 
Keywords: José del Perojo, Neokantism, Social Darwinism, Politics, Economy, Monism, Colonialism, "cuestión cubana"

\section{Biografía intelectual y política de José del Perojo}

Tosé del Perojo y Figueras, nacido en Santiago de Cuba el 19 de enero de 1850, inició sus estudios en Santander, provincia de donde provenía su padre, rico indiano que falleció tempranamente. Con la fortuna heredada, José del Perojo diseñó su propio programa de formación universitaria, lo que le llevó a viajar a Inglaterra, Francia y Alemania para obtener una educación que no creía poder encontrar en España. Especialmente significativo fue su paso por la Universidad de Heidelberg, donde conoció a Kuno Fischer (1824-1907), figura destacada de la Primera Escuela Neokantiana Alemana o Escuela de Heidelberg. La primera obra de Perojo fue el ensayo "Arthur Schopenhauer", publicado en 1875 en la Philosophische Monatshefte, de Leipzig, uno de los principales órganos culturales de los neokantianos.

Perojo creyó haber encontrado en el neokantismo la filosofía que podría servir de fundamento intelectual a la modernización de España en los campos científico, económico, social y cultural, así como el medio de superar la crisis en la que se veía inmerso el liberalismo español desde el fracaso del krausismo durante el sexenio revolucionario (1868-1874). A su regreso a la Península, se embarcó en el proyecto de renovar el panorama intelectual, difundir el pensamiento científico moderno y "europeizar" Espańa: primero, con la publicación en 1875 de sus Ensayos sobre el movimiento intelectual en Alemania, condenados en 1877 por el Vaticano debido a la defensa que en ellos se hace de las doctrinas naturalistas de Charles Darwin y Ernst Hæckel; segundo, con la fundación, en 
diciembre de 1875, de la Revista Contemporánea, principal publicación científica y cultural de la España de la época y plataforma publicitaria de las corrientes filosóficas más avanzadas, de la que fueron redactores jefes Rafael Montoro (1852-1933) y Manuel de la Revilla (1846-1881).

Perojo y Revilla participaron en la "tercera polémica de la ciencia española”, iniciada en 1876, en la que sostuvieron que en España no había habido más filosofía que la escolástica tomista debido a la perniciosa influencia de la intolerancia religiosa y el despotismo político, que acabaron con la libertad de pensamiento, unidos a un fallo esencial en el carácter nacional español que dificulta el desarrollo de la racionalidad y la ciencia modernas.

Perojo fundó en 1877 la revista La Naturaleza y la Editorial Perojo, de marcada orientación filosófica y científica, dedicada a ofrecer al público traducciones directas de obras de autores extranjeros para vivificar la cultura nacional al contacto con la europea. Entre ellas es preciso mencionar la primera versión al español del Origen de las especies, de Charles Darwin, y de las Obras filosóficas, de René Descartes, esta última debida a Revilla.

En 1879, Perojo se arruinó, cerró la editorial, vendió sus revistas y se trasladó a París, donde rehizo su fortuna. Después regresó a Espańa y retomó sus empresas culturales. Así, en 1883 tradujo una parte de la Crítica de la razón pura, de Immanuel Kant y en 1885, en colaboración con Enrique Camps, La descendencia del hombre y la selección en relación al sexo, de Darwin. A partir de entonces desplazó su interés de los problemas filosóficos a los económicos, sociales y políticos, en especial a los que afectaban a la relación de las colonias españolas con la metrópoli, aunque la impronta neokantiana nunca le abandonó. Promovió el trato, en principio igualitario, de los territorios ultramarinos para llegar a su total identificación con los peninsulares. Llevó a cabo esta defensa de las colonias desde su destacada labor como periodista y empre- 
sario cultural y desde los cargos políticos que desempeñó durante el resto de su vida.

Perojo inició en 1886 su actividad política pública como diputado fusionista por Caldas (Pontevedra). Ese mismo año se arruinó por segunda vez debido al elevado coste económico que le supuso la fundación y dirección del periódico La Opinión. En 1889 fue nombrado Gobernador Civil de Manila, puesto al que renunció en 1890. En 1891 y 1893 fue candidato por Santander, pero el fraude electoral institucionalizado le impidió ocupar el escańo que le pertenecía. Desilusionado, se alejó del fusionismo para vincularse al Partido Autonomista Cubano, y obtuvo en 1894 un escaño por La Habana. Ese mismo año fundó y dirigió el semanario El Nuevo Mundo (Nuevo Mundo desde 1895), su publicación más exitosa, que continuaría existiendo incluso tras su muerte, pues la familia Maeztu se encargó de mantener vivo el proyecto editorial de Perojo representado por esta revista. En 1898 fue reeligido diputado por La Habana. Defensor de la terminación de la Guerra de Cuba, manifestó su desconfianza hacia el sistema de la Restauración borbónica y abandonó la política. Así, en 1899 centró su actividad en empresas culturales, fundando la Editorial Nuevo Mundo y, en 1900, Por y el Sin embargo, en 1905 volvió a la política activa, siendo elegido diputado por Las Palmas de Gran Canaria en el seno del Partido Liberal Canario, relamente una coalición de varios partidos, en el que Perojo participó como representante del Partido Conservador de Antonio Maura, por quien profesó gran admiración y en quien influyó notablemente, pues Perojo fue, junto con su discípulo Ramiro de Maeztu, el gran teórico del neoconservadurismo español. Fundador de la Asociación de la Prensa Española, en 1906 centró su actividad en la defensa de la libertad de prensa. Pero en 1907, tras ser reelegido diputado por Las Palmas, inició una campaña a favor de la descentralización administrativa de las Islas Canarias. Ese mismo ańo empezó a de- 
dicar su atención periodística y política a las cuestiones educativas, publicando una de sus obras fundamentales, Ensayos sobre educación. En 1908 realizó frecuentes viajes a Inglaterra en compañía de Ramiro de Maeztu para comparar la situación de la educación en España respecto de Europa y reunió en el volumen La educación española algunos de los discursos parlamentarios que dedicó a esta cuestión. La actividad de Perojo en el ámbito de la política educativa española fue bastante intensa durante sus últimos años de vida.

José del Perojo murió el 17 de octubre de 1908 en su escaño del Parlamento, mientras escuchaba una réplica a una enmienda suya al proyecto de reforma de la administración local encaminada a lograr la división biprovincial de las Islas Canarias: división que no se produciría hasta la década de 1920 durante la dictadura del general Miguel Primo de Rivera.

De haber vivido, es muy probable que dicha enmienda se hubiera aprobado, lo que habría tenido gran impacto, no sólo en la estructura administrativa de las Canarias, sino en la de toda España, pues, en su ideario, España debía configurarse en torno a un poder central fuerte, podríamos decir que de corte autoritario y con un componente mesiánico aunque laico, pero también debía concederse una amplia autonomía administrativa a las regiones, provinvias y corporaciones locales, siempre que éstas reconocieran y acataran las decisiones tomadas, en ejercicio de sus funciones, por ese poder central. De hecho, este es el núcleo ideológico de lo que se denomina el "maurismo", es decir, del neoconservadurismo español de inicios del siglo XX. Un núcleo ideológico que sería desarrollado por Ramiro de Maeztu en las décadas posteriores, primero bajo el principio de la "democracia armada" y después de la "armada sin democracia" y fuente intelectual de lo que, de haber triunfado históricamente, podría haber llegado a constituir una suerte de fascismo español. 
El sentido que tiene este repaso de los presupuestos intelectuales y políticos de Perojo es comprender su impacto en la visión perojiana de las relaciones entre España y sus colonias, en general, y entre España y Cuba, en particular. Pues, como veremos a continuación, existe una sintonía plena entre las concepciones filosófico-naturalistas y el ideario político de Perojo y su propuesta de resolución de la "cuestión cubana".

\section{Neokantismo, darwinismo social y teoría de los partidos políticos}

Perojo cree encontrar en el neokantismo la filosofía que sirva de fundamento intelectual a la modernización de España. Además, el neokantismo tiene la virtud de pretender superar la dicotomía entre unos sistemas idealistas que carecen del debido fundamento empírico — pues se basan en la pura conciencia subjetiva de la persona - y el positivismo, que incurre en la mera acumulación de hechos imposibles de articular entre sí. En cambio, el neokantismo propone una vuelta al pensamiento de Kant, entendido éste en sentido amplio, como corriente "madre" u origen de las diversas doctrinas, tanto científicas como filosóficas, surgidas desde el siglo XVIII. Por tanto, se trata de una lectura positivista o empirista de Kant, pero que intenta no caer en los excesos de la filosofía desarrollada por Comte.

En este sentido, la filosofía que Perojo trae a España se caracteriza, primero, por su rechazo a la metafísica, entendida - en términos kantianos - como especulación vacía, sin límites, sin base empírica, en la que se ve inmerso el idealismo, en general, y el krausismo, en particular. En segundo lugar, establece numerosos puntos de contacto con las doctrinas de Spencer: necesidad de dotar de objeto a la filosofía, de delimitar los distintos campos de conocimiento (ciencia, filosofía...) y de reconocer límites 
al conocimiento humano; afirmación de un "monismo crítico", de carácter científico, según el cual materia y espíritu no son sino manifestaciones de una única realidad, de manera que hay una ley común a todos los fenómenos naturales, que no es otra que la causalidad; creencia en el progreso general de la humanidad y en la evolución de las especies, por lo que entronca con la teoría del darwinismo social. En tercer lugar, resalta la importancia de la experiencia, de los hechos ("fenómenos", en terminología kantiana, o "lo cognoscible", en lenguaje spenceriano). Pero, en cuarto lugar, esta proximidad al positivismo — sobre todo al anglosajón- no supone una identificación, ya que justifica y legitima el objeto de la filosofía asignando a la reflexión filosófica dos funciones principales: la de crítica de conocimiento, en especial del conocimiento científico (epistemología), y la de elaborar síntesis totalizadoras a partir de las aportaciones de los saberes científicos modernos, de los saberes científicos positivos, de las ciencias particulares.

Así se rompe con la concepción idealista de la filosofía como saber puramente especulativo, puesto que la filosofía se fundamenta en la experiencia empírica y pasa a estar íntimamente relacionada con la ciencia. Y, a la vez, se rechazan los excesos empiristas de un positivismo que reduce la realidad a un conjunto de hechos cuyo conocimiento corresponde a una multitud de saberes particulares inconexos entre sí. Ahora, señala a la filosofía la tarea de servir de nexo de unión entre dichos saberes, convirtiéndola en una metaciencia encargada de articular las diversas ciencias particulares, que antes parecían independientes entre sí.

Perojo cree que, para impedir que se frene el pensamiento, debe darse en él una variedad, una discusión entre las diversas corrientes que aquél tiene y en las que se manifiesta: esto es lo que permite el desarrollo de la cultura y evita caer en la inmovilidad y el enquistamiento en una única línea o escuela de pensamiento. A partir de este rechazo al exclusivismo, surge su firme voluntad de 
no aceptar nunca un único sistema filosófico como verdadero y, por extensión, su crítica al krausismo, que él interpreta como una doctrina dogmática y opresiva con pretensiones exclusivistas. En este sentido, los sistemas idealistas no serían, según Perojo, más que "andadores intelectuales, propios para caracteres infantiles" y la filosofía es un conjunto de sistemas en lucha por la existencia, en el que ninguno logra nunca la victoria definitiva sobre los demás.

Si esto se refiere al campo más estrictamente teórico, en el plano práctico, Perojo ve el neokantismo, por un lado, como un medio de superar la crisis del liberalismo español, ya que muchos liberales españoles achacan al krausismo no haber sido capaz de ofrecerle la base intelectual que precisa: el fracaso del Sexenio revolucionario hace que los liberales demanden un tipo de pensamiento distinto del idealismo krausista, pues la base metafísica en la que aquel se sustenta es considerada poco operativa a la hora de encarar las necesidades de España. Por otro lado, el neokantismo introduce en la cultura espańola una actitud gnoseológica más rigurosa en lo que se refiere al tratamiento de los problemas filosóficos y, en concreto, rechaza las argumentaciones de tipo retórico, moralista o esteticista a la hora de abordar problemas de carácter científico.

Si Perojo muestra su posición en favor de la aplicación de las doctrinas transformistas darwinistas en el plano estrictamente filosófico, en el plano antropológico también asume plenamente las doctrinas del darwinismo social, es decir, de la extrapolación de las doctrinas de Darwin a la esfera social. Así, una doctrina que en origen sólo hacía referencia al ámbito propio de la ciencia biológica se convierte en auténtico principio explicativo de la realidad. Dicho de otro modo, con Spencer, las doctrinas transformistas se convierten en auténtica doctrina evolucionista de la realidad, pues la realidad — recordemos - es una (monismo) y por tanto, se ha de guiar por unas leyes que han de ser iguales para todos sus ámbitos: la teoría de la evolución de las especies y la lucha por la existencia 
son elevados al rango de doctrina explicativa de todo lo que ha sido, es y será en el universo.

En cuanto al plano ideológico, Perojo asume la teoría de los partidos políticos desarrollada por Johann Caspar Bluntschli, según la cual en la juventud se milita en los partidos radicales y revolucionarios, en la madurez se pasa a pertencer a los partidos reformistas y en la senectud se milita en los partidos más conservadores. Es decir, que también en el plano ideológico operan las mismas leyes que provienen de la teoría evolucionista, pues la vida de cada persona reproduce el desarrollo de la vida de las especies: la ontogénesis es un fiel reflejo de la filogénesis. Puesto que, recordemos, la realidad es una y en ella operan unas y las mismas leyes que la rigen, la persona responde al mismo patrón explicativo que se aplica a todos los demás componentes de esa realidad.

De esta manera, comprobamos cómo el pensamiento social de Perojo surge de su pensamiento filosófico y su pensamiento político de su pensamiento social: a partir de su concepción monista desenvuelve su darwinismo social y a partir de éste desarrolla su devenir ideológico, que él mismo seguirá al pie de la letra a lo largo de su vida, desde su temprana militancia en el Partido Liberal Cubano, pasando por su pertenencia al Partido Fusionista y acabando por su activa participación en el giro "maurista" del Partido Conservador.

3. El monismo, el darwinismo social y la teoría de los partidos políticos aplicados a la "cuestión cubana"

En 1879 se produce el primer intento de participación de Perojo en la política cuando se presenta a las elecciones de abril como candidato por La Habana del Partido Liberal Cubano, aunque no es elegido como consecuencia del régimen político caciquil existente tanto en las Antillas como en la Península y del sistema electoral 
especial que rige en Cuba, y que está encaminado a asegurar el triunfo automático de los ultraconservadores de la Unión Constitucional. Justo dos años después, en 1881, vuelve a probar suerte, presentándose una vez más candidato por el mismo partido y circunscripción, aunque nuevamente resulta derrotado por idénticos motivos.

En 1884 visita las fábricas de azúcar de remolacha de Silesia junto a un diputado francés, lo que le permite aumentar su conocimiento sobre la producción azucarera y reunir nuevos datos para poder comparar la situación de la principal industria cubana con la de otras zonas de producción. Por eso, cuando reasume decididamente su labor como publicista, mantiene siempre esa marcada tendencia hacia los temas relacionados con las posesiones españolas de ultramar. Así, de los 18 artículos que escribe ese año —algunos de ellos divididos en partes, que publica a lo largo de varios días-, 16 abordan cuestiones coloniales que hacen especial referencia a Cuba. Entre ellos, hay que mencionar los que se refieren a la polémica sostenida con Juan Gualberto Gómez, autonomista cubano.

Para entender esta polémica, hay que señalar primero que cuando en 1881 el Partido Liberal Cubano asume abiertamente un ideario autonomista para la Gran Antilla, Perojo se decanta por el unitarismo, se aparta de aquél y se vincula al Partido Fusionista de Sagasta, que despliega su actividad en la Península, generando en sus antiguos correligionarios cierto resentimiento. Perojo había sido elegido candidato por el partido cubano en 1879 y 1881 gracias al impulso que había dado a su candidatura Rafael Montoro, por entonces vocal de su Junta Directiva. No obstante, él había aceptado pertenecer al partido, a pesar de sospechar que era ocultamente autonomista, básicamente por su amistad con Montoro y porque creía haber encontrado en él un lugar de unión entre las diversas corrientes de la ciudadanía cubana deseosa de reformas económicas, sociales y administrativas. 
En segundo lugar, los políticos cubanos consideran a Perojo un "recién llegado" que desconoce los verdaderos problemas y aspiraciones de la isla, y que sólo ha empezado a interesarse por ellos en fecha muy Aunque esto no es totalmente cierto, sí tiene fundamento la crítica que Gómez le hace, en el sentido de que en el periodo de la sangrienta "Guerra de los diez años" (1868-1878), Perojo se había inhibido bastante y había centrado su pluma más en cuestiones filosóficas, como la difusión de Kant y el neokantismo, que en los problemas políticos, sociales, económicos, etc., de las colonias antillanas ${ }^{1}$. Además, a los autonomistas les disgusta la defensa que hace Perojo de la total identificación de los territorios ultramarinos con los de la Península, convirtiéndolos en otras provincias más, con el mismo estatus jurídico y los mismos derechos y deberes. Y más aún, que base su postura en una hipotética recuperación de la antigua tradición española, que, según Perojo, tenía un sentido igualitario que promovía para las colonias un trato idéntico al de los diversos territorios de la metrópoli.

Por fin, las iras de los autonomistas se desatan al leer cuatro artículos que escribe Perojo para el diario republicano El Progreso ${ }^{2}$, en los que manifiesta una opinión nada positiva hacia sus antiguos compañeros del ahora denominado Partido Autonomista Cubano, al tiempo que se dedica a desentrañar las actitudes contradictorias que han mantenido en diversos momentos de su quehacer político y a resaltar los importantes cambios que ha ido operando

${ }^{1}$ Así lo señala Juan Gualberto Gómez: “[...] cuando parecía que ninguno podía permanecer extrańo en la contienda, el Sr. del Perojo, ni de Cuba se acordaba, ni tenía opinión respecto a los graves asuntos que en ella se debatían [...], sino que entretenía sus ocios y derrochaba ese tiempo [...] en averiguar si Kant estaba en lo cierto o si Krause andaba errado..." (26 de julio de 1884).

2 "Los partidos peninsulares y su política transmarina" (2 de junio), "Los partidos antillanos. La teoría del Partido Autonomista" (6 de junio), "El Partido Autonomista Cubano. Su doctrina económica" (11 de junio) y "Los partidos antillanos. ¿Conviene a Cuba la autonomía?” (16 de junio). 
su ideario político manifiesto. Estos cuatro artículos son el origen inmediato de la polémica, aunque ya hemos visto que tiene otro remoto, que viene de años atrás.

La discusión se desarrolla de julio a septiembre de 1884 , a lo largo de tres artículos de Perojo (divididos en siete partes, publicadas en otros tantos días) y cuatro artículos de Gómez (divididos en nueve partes), y adopta tintes realmente violentos, con acusaciones mutuas, réplicas y contrarréplicas, en las que Perojo acaba por adoptar una actitud racista y propia del darwinismo social cuando se explica la postura de Gómez apelando a su condición de mulato, frente al propio Perojo, que se declara superior por su condición de blanco y europeo. En concreto, Perojo afirma, literalmente, que él (Perojo) es "darwinista rancio y acérrimo partidario del escalonamiento físico y moral de las razas. Esto sentado, considere mi adversario la chacota y cuchufleta que otro menos frío podría enhilarle al verle echárselas de dómine discrepante y de buido catedrático con un individuo de raza indo germánica que entre los suyos tiene probado que no es manco ni de los más torpes" (21 de agosto de 1884).

Y en una fase posterior de la polémica incluye afirmaciones en el sentido en que los fundadores del darwinismo, Darwin incluido, no dudarían que, enfrentados dos rivales, las probabilidades de éxito están del lado del miembro de la "raza superior", que el tamaño medio del cráneo de unas y otras razas muestra las diferentes capacidades intelectuales de cada una de ellas, y que está demostrado "que las diferencias anatómicas en el músculo motor de la lengua, el estiloglosa, son las que explican el singular lenguaje de los negros catedráticos de La Habana” (2 de septiembre de 1884). ${ }^{3}$

${ }^{3}$ El resto de los argumentos racistas reseñados en este párrafo los expone en esa misma parte del artículo citado y en la primera, publicada el 1 de septiembre de 1884 . 
A este respecto, debemos señalar cómo el racismo de Perojo se evidencia también en artículos como "La raza negra" y "La república negra", publicados bajo el significativo seudónimo de "Germanus" en La Opinión (4 y 15 de junio de 1886), en los que arremete contra la "bestia negra" (en este caso, en sentido literal), que para él se encarna en Haití.

Pero, en el fondo, lo que Perojo está haciendo no es más que aplicar a la "cuestión cubana", de forma rigurosa, su pensamiento filosófico, social y político: 1) la realidad es una y por eso la estructura administrativa y jurídica debe ser también una (asimilación) y nunca debe entenderse la reivindicación de autonomía para Cuba como un paso en el camino para lograr la independencia; 2) la biología demuestra, de acuerdo con la doctrina evolucionista, que hay razas naturalmente dominadoras y razas naturalmente dominadas, las primeras destinadas a perpetuarse y mejorarse y las segundas a extinguirse (darwinismo social).

Efectivamente, esto se proyecta en su visión de las relaciones entre los pueblos y razas humanas, vinculada estrechamente al darwinismo social que profesa, aunque en esto no hace más que seguir las ideas que ya había expuesto su amigo Pedro Estassen, economista catalán imbuido por las doctrinas positivistas, en el prólogo que precede a su traducción de la obra de Walter Bagehot, Leyes cientificas del desenvolvimiento de las naciones en su relación con las leyes de la selección natural y de la herencia.

En dicha traducción, publicada en la Biblioteca Perojo en 1877, Estassen afirmaba literalmente que:

La historia de las razas humanas nos demuestra la existencia de la selección natural: los más fuertes vencían a los más débiles y nada es más fácil de probar que un pueblo es más fuerte cuando está regido por un gobierno, que cuando carece de él. Sólo algunas naciones son aptas para mejorarse y desenvolverse [...] El secreto del proceso queda explicado en la teoría de la selección natural 
[...] El análisis metódico de los sucesos históricos, partiendo de las conclusiones de la biología, es el único medio de estudiar la ciencia social con fruto [...] Proclamar la igualdad humana cuando la naturaleza nos ha hecho a todos desiguales, y en una época en que la desigualdad era lo que mantenía el estado social, hubiera sido la expresión de una sensiblería ajena al espíritu de un gran sabio como lo era Aristóteles. La idea de igualdad humana ha dificultado siempre la selección, y si tales escrúpulos hubieran detenido al más fuerte, jamás habría tenido lugar la colonización. Los hombres que sacrificamos en provecho propio, no son iguales a nosotros; si lo fueran, sería imposible destruirlos; pues se defenderían con iguales ventajas que los que atacan, esto es por lo que toca a la parte material de la cuestión. La raza que domina reduce a esclavitud a la dominada, y como el refinamiento de las costumbres sólo es compatible con los momentos de ocio, la esclavitud da por primera vez el ocio apetecido (Bagehot, 1877, passim).

$\mathrm{Al}$ año siguiente de ser elegido como diputado fusionista por Caldas, es decir, en 1887, Perojo mantiene su atención en los problemas coloniales con tres discursos enmarcados en los debates que, sobre las posibles reformas para Cuba, se desarrollan en el Congreso a partir de la primavera. En estos discursos del 9 y 14 de mayo y 21 de junio, manifiesta su posición intermedia entre sus antiguos correligionarios cubanos - Montoro, entre ellos-, que ahora son autonomistas, y los ultraconservadores, también cubanos, de la Unión Constitucional. En concreto, reprocha a los primeros su exceso de ingenuidad y excesivo idealismo, mientras que carga las tintas en los segundos, a los que acusa de inmovilismo y de oponerse sistemáticamente a cualquier tipo de reformas en las colonias. Inmediatamente después de hacer públicos los dos primeros discursos, Perojo los publica bajo el título La cuestión de Cuba (Madrid, Imprenta de los Hijos de J. A. García, 1887). También dedica a la realidad colonial sus discursos de los días 15 y 16 de enero y 7 de mayo de 1888 . 
Perojo interrumpe su actividad política en ese sentido al ser nombrado por Manuel Becerra, Ministro de Ultramar, "Jefe de Administración de primera clase, Gobernador Civil de Manila”, el 5 de abril de 1889. A inicio de mayo parte rumbo a ese archipiélago, arribando a su destino el 4 de junio, donde toma posesión de su cargo y de otros dos anexos: Corregidor y Vicepresidente del Excelentísimo Ayuntamiento de Manila.

La prensa de esa ciudad le pone inmediatamente en antecedentes, pues existe algún recelo hacia él por su desconocimiento de la realidad y peculiaridades de la sociedad filipina. De hecho, su mentalidad europea y europeísta orientada a la tarea de modernizar Manila choca con el enorme atraso que padecen sus habitantes y con la existencia de tradiciones sociales y políticas muy arraigadas, como son unas prácticas caciquiles mucho más exacerbadas que en la Península. Aun así, asume rápidamente sus nuevas responsabilidades sin ahorrar esfuerzo alguno: sus inspecciones de manglares, arrabales y de los barrios de Manila en general son muy frecuentes, a fin de comprobar personalmente la situación en la que se encuentra la ciudad. Esas inspecciones cambian radicalmente su apreciación acerca de cuál debe ser su labor: no se trata, como pensaba inicialmente, de embellecer Manila, sino de procurar a su población las infraestructuras mínimas, de las que aún carece. Por eso, deja de lado sus proyectos de mejora estética de la ciudad en favor de otras medidas y actuaciones más perentorias. Destacan sus actuaciones para mejorar las condiciones higiénicas de la ciudad, sus proyectos de construcción de obras públicas y sus bandos destinados a dotar a las instituciones educativas de mejores recursos materiales, sobre todo pecuniarios.

Sin embargo, sus esfuerzos chocan contra los intereses creados de los caciques, que logran frenar muchos de los planes aprobados, e incluso abortan no pocos de ellos aun antes de que entren en vigor. La corrupción administrativa está a la orden del día, llegando 
en algún caso a extremos realmente graves, como lo es el de las obras del puerto, cuyo plan se había aprobado en 1880 y que se había dotado económicamente a través de un impuesto especial, con el fin de que las obras estuvieran terminadas en 1888. Perojo descubre con sorpresa que ni siquiera se han iniciado y que grandes sumas de dinero presupuestado y recaudado al efecto han desaparecido sin dejar rastro para cuando él es nombrado Gobernador. En cuanto al proyecto de sustitución de las obsoletas murallas de Manila por modernas fortificaciones, comprueba que se encuentra en proceso de tramitación desde 1885, todavía pendiente de aprobación. Por si fuera poco, cuando intenta imponerse, desde la dignidad de su cargo, a los manejos caciquiles y acabar con la corrupción en la gestión de las obras públicas descubre que su posición es totalmente ineficaz frente a las competencias - legales o de facto- que posee el Presidente de las Obras del Puerto. ${ }^{4}$

Desengañado al sentirse incapaz de erradicar la corrupción y acabar con el dominio de los caciques, Perojo presenta la renuncia a su cargo el 8 de julio de 1890, siendo declarado cesante el 1 de agosto. El 18 de septiembre es despedido por los concejales del Ayuntamiento de Manila, y parte en un vapor con destino a Hong Kong y Emuy, con el propósito de visitar también Tonkín, Java y la India, para conocer más a fondo la administración colonial británica y francesa.

A su regreso a España, en 1891, se manifiesta un cambio en su orientación política, al decidir su adhesión al Partido Autonomista Cubano, cuya posición había censurado durante la década anterior. Aparte de las relaciones afectivas que le unen a su amigo

${ }^{4}$ El propio Perojo denuncia en un discurso en el Congreso, el 21 de junio de 1898, la corrupción, desidia y multitud de errores administrativos y gubernamentales que él había podido constatar durante su estancia en Manila, que no son —en su opinión — más que ejemplos de la aceleración en el proceso de desmoronamiento al que se encamina Espańa. 
Montoro, es posible que su experiencia en Filipinas tenga que ver en ello. Aunque esto no signifique que deje de confiar totalmente en Sagasta y el fusionismo.

Alejado de la actividad parlamentaria, retoma la periodística centrándose, como es de suponer, en las cuestiones coloniales, en general, y en las que afectan a Cuba, en particular. Así, destacan sus artículos de índole económica, como los que abordan los problemas de las principales producciones cubanas (azúcar y tabaco) y de las relaciones comerciales de las Antillas con la Península y con Estados Unidos. Por eso, de los cinco artículos que publica, cuatro van directa o indirectamente referidos a estos temas. ${ }^{5}$ También se refiere a ellos la ponencia que lee en la cuarta sesión del Congreso Geográfico Hispano-Portugués-Americano, intitulada "Comercio de España con las Repúblicas Hispano-Americanas. ${ }^{6}$ En cuanto al quinto artículo (30 de noviembre) versa también sobre cuestiones económicas. En todos ellos, abundan las cifras y las estadísticas, siguiendo una costumbre que mantiene desde sus días de formación neokantiana, que le ha proporcionado un gran respeto por los datos positivos, contrastados científicamente, y lo ha convertido en un perito en cuestiones económicas y comerciales.

Como complemento de esta actividad periodística, Perojo vuelve a estar presente en el Congreso, al obtener un escaño como diputado del Partido Autonomista Cubano por La Habana. En sus discursos del 1 de mayo y 27 de noviembre, manifiesta su actitud, típicamente liberal, a medio camino entre el revolucionarismo de

5 "El impuesto sobre el azúcar" (13 de febrero), "El convenio con los Estados Unidos" (25 de febrero), "Intereses castellanos y cubanos (las harinas)" (26 de marzo) y "Los azúcares peninsulares y los de Ultramar" (3 de mayo). Todos ellos son publicados en el periódico El Liberal, de Madrid, pues Perojo cuenta con el apoyo de su director, Miguel Moya, afecto al ideario autonomista y diputado por Cuba en varias legislaturas.

${ }^{6}$ Es publicada con el resto de comunicaciones en un volumen editado en Madrid por la Librería Gutenberg, Tipografía Franco-Española, pp. 395-424. 
los independentistas cubanos y el constitucionalismo intransigente de los conservadores de la Gran Antilla. La postura política de Perojo no deja de ser compleja, pues pretende ser autonomista sin renunciar por ello al fusionismo. Tal vez está empezando a ser consciente de hasta qué punto el sistema de la Restauración está en crisis, como consecuencia de su incapacidad para dar respuesta a las necesidades y demandas de la sociedad espańola, que en su mayoría permanece ajena a ese sistema que dice representarla pero que no lo hace realmente. Quizá su desencanto por la política activa en esas condiciones le impulse a buscar los medios de comunicación social para hacer públicas sus reflexiones acerca de la situación. En cualquier caso, descuida notablemente sus funciones como diputado y pronto abandona el Parlamento al abrirse una nueva etapa política con el fin del turno liberal y el inicio del conservador.

Entre 1894 y 1896 publica numerosos artículos de índole económica, política y social, la mayoría referidos a Cuba, y todos ellos desde su tribuna de El Nuevo Mundo y arrecian sus críticas al Partido Conservador y su fe en el Partido Fusionista. Según Perojo, en manos de los conservadores está la responsabilidad de poner fin a la insurrección en Cuba o condenar a la colonia y a la metrópoli a una guerra indefinida, de desastrosas consecuencias para todos. La ineficacia de la labor de Martínez Campos y la cruel estrategia de Weyler van acabando con las esperanzas que tiene de una solución

${ }^{7}$ En 1894, "Transacciones necesarias, transacciones temerarias" y "Boletín comercial. Azúcares peninsulares" (15 de febrero), "Desde Bilbao" (23 de agosto), "La industria metalúrgica en España" (6 de septiembre) y "El mal nacional y las reformas de Cuba" (18 de octubre). En 1895, coincidiendo con el cambio de nombre del semanario por Nuevo Mundo, "Insurrección en Cuba" (14 de marzo), "La política en Cuba" ( 21 de marzo), "Catalanes y cubanos" (2, 16 y 23 de mayo), "Política lamentable" (25 de julio), "Incurables" (3 de octubre), "Nuestra mejor aliada" (24 de octubre) y "El dilema" (31 de octubre). En 1896, "Los comisionados de Puerto Rico" (22 de octubre). 
consensuada entre los partidarios de reformar radicalmente la administración colonial y sus órganos de representación política y los defensores de la línea dura y la "solución" militar.

Perojo intenta, a la desesperada, imponer lo que él considera que es algo de cordura, mediando entre las posturas más extremas, y consigue ser designado candidato del Partido Autonomista $\mathrm{Cu}-$ bano a las elecciones de marzo de 1898 por las circunscripciones de Santiago de Cuba y Ponce (Puerto Rico). Es elegido por la primera, quedando la segunda en suspenso, pendiente de dictamen. Desde su tribuna pronuncia en el hemiciclo sendos discursos sobre la situación en Cuba y la necesidad de tomar medidas urgentes lo suficientemente aceptables para todas las partes en conflicto, con el fin de desactivarlo (20 de junio). Al día siguiente reincide en la problemática colonial, aunque esta vez se centra en el caso filipino, del que tiene algún conocimiento desde sus tiempos de Gobernador de Manila. Critica abiertamente el plan de reforma del Ministro Segismundo Moret, que considera insuficiente, en vista de las circunstancias, por ser inaceptable para los insurgentes, y defiende la terminación de la guerra, aunque sea a costa de sacrificar mucho más de lo que están dispuestos los liberales. En vista de la actitud de éstos, Perojo se siente cada vez más distanciado del fusionismo. El desencanto de Perojo hacia la política activa es más que evidente y desemboca en un discurso, pronunciado el 11 de septiembre, en el que confiesa abiertamente, en pleno Congreso, su desconfianza hacia el sistema político de la Restauración, y hacia la estructura y la propia actividad parlamentarias, anunciando, además, su deseo de abandonar definitivamente la política activa, que parece no tener ya sentido ni utilidad.

Tras la independencia de Cuba, se plantea seriamente abandonar la Península y marcharse a su tierra natal, al igual que han hecho otros correligionarios, como su amigo Montoro, que se va a convertir en uno de los ministros del nuevo gabinete de la Cuba 
"emancipada” y propone a Perojo utilizar sus influencias para conseguirle un puesto en el nuevo gobierno bajo protectorado de los Estados Unidos de Norteamérica. Sin embargo, Perojo decide permanecer en España, a pesar de que no le parezca una solución satisfactoria. Parece poco probable que, después de todo lo que había pasado, estuviera dispuesto a aceptar formar parte de una Cuba independiente y dirigir una sociedad en la que abundaban los ciudadanos chinos, negros y mulatos: al menos esa es nuestra apreciación. Aunque, como señalamos más arriba, de hecho se lo planteó durante un tiempo, quizá sopesando la posibilidad de llevar adelante un proyecto de europeización de Cuba y de creación, desde cero, de un cuerpo político que reflejara su propio proyecto ideológico.

Pasados los primeros años de desencanto y crisis personal, y tras un periodo de ensimismamiento en sus empresas periodísticas, Perojo decide retomar la actividad política, que parecía haber abandonado irrevocablemente. Así, presenta su candidatura en septiembre de 1905, aunque esta vez por el Partido Conservador. Este aparente viraje político del liberal reformista Perojo hacia el conservadurismo se explica en parte por la pérdida de crédito que, a sus ojos, ha tenido el Partido Fusionista y por la emergencia, en el campo conservador, del complejo fenómeno "maurista". Sin duda, la atracción que había sentido Perojo hacia la figura de Antonio Maura desde que éste presentara en 1893 sus famosos proyectos de reforma para las Antillas tiene mucho que ver con esta decisión. Además, es preciso recordar que los partidos políticos de aquel entonces eran más bien grupos de notables unidos, en ocasiones, por intereses muy variados que les permitían mantener y defender posiciones bastante distintas a las de sus presuntos correligionarios, e incluso contrarias. $\mathrm{O}$ sea, que a la hora de vincularse a un partido, pesaban más los lazos de afecto personal e individual que un corpus ideológico bien definido, estable y comúnmente aceptado al 
que todos se sometieran, que no existía realmente. Eso es lo que permite a Perojo militar en el conservadurismo sin abandonar su ideario liberal y reformista. Eso sí, entendiendo este ideario liberal y reformista no en el sentido en que es habitual en España, sino en el sentido que tiene en el mundo anglosajón ${ }^{8}$.

${ }^{8}$ El sentido que tiene el término liberal en la tradición española es muy diferente, por no decir contrario, al que tiene en la tradición anglosajona. En síntesis, para la tradición anglosajona el liberalismo económico parte de la iniciativa de los individuos que, a través del ejercicio de una libertad individual sin restricciones en un mercado sin regulación, se enriquecen a través de su actividad productiva, comercial y especulativa, y el sistema político y social que se deriva de esto tiene su núcleo en el predominio absoluto de la sociedad civil frente al Estado, condenado a desaparecer una vez que la sociedad civil pueda hacerse cargo de forma efectiva de todas las funciones que le son atribuidas. En cambio, para el liberalismo español la reivindicación de las libertades individuales debe ir siempre acompańada del respeto a los derechos colectivos de toda la sociedad en su conjunto, en un marco económico en el que los individuos se pueden enriquecer a través de su actividad productiva, comercial y especulativa, pero en un mercado regulado que evite los abusos que necesariamente se producen por el egoísmo y la codicia de los individuos. El sistema y social que se deriva de esa concepción española del liberalismo tiene su núcleo en el equilibrio entre la sociedad civil y el Estado, de tal forma que cada uno de ellos tiene asignadas unas funciones y un ámbito de actuación propios que el otro debe respetar inviolado, siempre que ninguno de ellos, sociedad civil y Estado, se extralimite en sus funciones. De hecho, si se aprecia, el liberalismo español establece como límite de la libertad individual que ésta no atente contra las libertades colectivas $\mathrm{y}$, de hecho, fueron los liberales del siglo XX quienes empezaron a introducir en España, a través de la acción del Estado, lo que hoy en día se denomina estado de bienestar: toda una serie de mecanismos de protección social entre los que cabe destacar una educación y sanidad públicas y universales para todos los ciudadanos. En este sentido, para el liberalismo español, el liberalismo anglosajón no sería en sentido estricto un liberalismo, sino una forma de conservadurismo más o menos camuflada. Y, en términos actuales, el liberalismo español podría ser considerado como algo que está en la línea de lo que se conoce como socialdemocracia. 
Convertido en uno de los personajes centrales del círculo íntimo de Maura, Perojo se encarga de sentar los fundamentos del neoconservadurismo espańol, separado ya del viejo pensamiento reaccionario de comienzos del XIX y de las variantes que éste había tenido a lo largo del siglo (carlistas, neocatólicos, "mestizos", etcétera), estableciéndolos ahora sobre bases ideológicas heredadas de las clases medias inglesas, con un carácter laico, defensor de valores próximos a la tradición protestante (trabajo, riqueza, dinero) y fuertemente europeísta.

Pero esta es una cuestión que no atańe ya al planteamiento de Perojo en torno a la cuestión cubana.

\section{Bibliografía}

Anónimo, 1875, "Die Philosophie in Spanien", Philosophische Monatshefte, Leipzig, XI Band.

Bagehot, Walter, 1877, Origen de las naciones o leyes del desarrollo científico de los pueblos según la ley de la selección, Pedro Estassen (trad. e intro), Madrid, Perojo (Biblioteca Perojo).

Darwin, Charles, 1876, El origen del hombre. La selección naturaly la sexual, Barcelona, Imprenta de la Renaixensa.'

\footnotetext{
${ }^{9}$ No se indica traductor, pero Diego Núńez ha determinado que, casi con total seguridad, se debió a Joaquín Bartrina, poeta catalán vinculado al fenómeno de la Renaixensa, y que omitió su nombre para no ser objeto de represalias por parte de las instancias oficiales de la Iglesia católica, ferozmente opuesta la difusión de las doctrinas darwinianas y que tenía una enorme influencia política y social en España. El propio Perojo vio cómo sus Ensayos sobre el movimiento intelectual en Alemania eran incluidos en el Index librorum prohibitorum: for difundir las doctrinas naturalistas más avanzadas, incluidas las de Darwin y Haeckel. También fue prohibida, posteriormente, la traducción que hizo Perojo de la Crítica de la razón pura, porque las doctrinas kantianas eran consideradas sospechosas. Suponemos que también sería prohibida la traducción de Perojo y Enrique
} 
, 1877, Origen de las especies por medio de la selección natural o la conservación de las razas favorecidas en la lucha por la existencia, E. Godínez Madrid (trad.), Perojo (Biblioteca Perojo).

, 1885, La descendencia del hombre y la selección en relación al sexo, José del Perojo y Enrique Camps (trad.), Madrid, Rivadeneyra.

Díaz Regadera, María Dolores et al. (estudio introductorio, edición y notas), 2003, Artículos filosóficos y políticos de José del Perojo (1875-1908), Ediciones de la Universidad Autónoma de Madrid (Estudios, 86).

Díaz Regadera, María Dolores, 1996, José del Perojo y Figueras (1850-1908). Neokantismo y reformismo, Ediciones de la Universidad Autónoma de Madrid (Tesis en microficha).

Dorca, Toni, 1998, Los albores de la crítica moderna en España: José del Perojo, Manuel de la Revilla y la "Revista Contemporánea", Valladolid, Universitas Castellae (Anejos Siglo Diecinueve. Monografías, 3).

Gómez, Juan Gualberto, 1 y 5 de julio de 1884, "Los autonomistas cubanos", El Progreso, Madrid.

, "Para rectificar", 26 de julio y 4 de agosto de $1884, E l$ Progreso, Madrid. drid.

, 22 de agosto de 1884, "Última palabra", El Progreso, Ma, 4 y 6 de septiembre de 1884, "Resumen del debate", $E l$ Progreso, Madrid.

Gubern, Román, 1994, Benito Perojo. Pionerismo y supervivencia, Madrid, Filmoteca Española / Instituto de a Cinematografía y de las Artes Audiovisuales.

Camps de La descendencia del hombre y la selección en relación al sexo, de Darwin, aunque en este caso no hemos encontrado pruebas que lo demuestren. 
Haeckel, Ernesto, 1879, Historia de la creación natural o doctrina científica de la evolución, Pedro Estassen (prol.), Madrid, Editorial Perojo (Biblioteca Perojo).

Hermida, Fernando et al. (estudio intro., ed. y notas), 2006, Manuel de la Revilla: Obras completa, tt. I, II y III, Ediciones de la Universidad Autónoma de Madrid.

Kant, Inmanuel, 1883, Crítica de la razón pura, José del Perojo (trad.), Madrid, Gaspart (Manuel G. Hernández).

Maeztu Whitney, Ramiro de, 20 de febrero de 1908, "Lo de las escuelas", Nuevo Mundo, Madrid.

, 30 de abril de 1908, "Gladstone y la obstrucción”, Nuevo Mundo, Madrid.

, 17 de septiembre de 1908, "La comisión de maestros", Nuevo Mundo, Madrid.

, 24 de septiembre de 1908, "El Congreso de Educación moral", Nuevo Mundo, Madrid.

, 22 de octubre de 1908, "Grandmontagne en América", Nuevo Mundo, Madrid.

, 29 de octubre de 1908, "Nuestro muerto", Nuevo Mundo, Madrid.

Menéndez Pelayo, Marcelino, 30 de julio de 1876, "Mr. Masson, redivivo", Revista Europea, Madrid.

, 24 de septiembre de 1876, "Mr. Masson, redimuerto", Revista Europea, Madrid.

Núñez, Diego, 1975, La mentalidad positiva en España: desarrollo y crisis, Madrid, Túcar.

Perojo Figueras, José del, 1875, Ensayos sobre el movimiento intelectual en Alemania. Primera serie, Madrid, Imprenta de Medina y Navarro. 
, "Kant y los filósofos contemporáneos", 21 de marzo de 1875, Revista Europea, Madrid.

, 30 de mayo y 6 de junio de 1875, "La Antropología y el Naturalismo", El Tiempo, Madrid.

, 27 de junio de 1875, "Objeto de la Filosofía en nuestros tiempos”, El Tiempo, Madrid.

, 4 de julio de 1875, "La historiografía en Alemania", Revista Europea, Madrid.

, 25 de julio y 1 de agosto de 1875, “Teoría de los partidos políticos", Revista Europea, Madrid.

, 15 de enero de 1876, "Haeckel juzgado por Hartmann", Revista Contemporánea, Madrid.

, 15 de abril de 1877, "La Ciencia española bajo la Inquisición”, Revista Contemporánea, Madrid.

, 15 de septiembre de 1877, "Análisis y ensayos. El positivismo o sistema de las ciencias experimentales, por Pedro Estassen, Barcelona, Jané Hermanos", Revista Contemporánea, Madrid.

, 1883a, Cuestiones coloniales, Madrid, Librería de Fernando Fe.

, 1883b, La colonisation espagnole (Conférence du 10 Septembre, 1883). Ámsterdam, Schröder Frères.

, 7 de marzo de 1884, "La crisis en Cuba y los derechos de exportación”, El Progreso, Madrid.

Madrid.

, 21 de marzo de 1884, "La ruina de Cuba", El Progreso,

, 2 de junio de 1884, "Los partidos peninsulares y su política transmarina”, El Progreso, Madrid.

, 6 de junio de 1884, "Los partidos antillanos. La teoría del partido autonomista", El Progreso, Madrid. 
, 11 de junio de 1884, "El Partido autonomista cubano. Su doctrina económica”, El Progreso, Madrid.

, 15 de junio de 1884, "Cantidad y valor del oro y la plata extraídos de las minas de América durante la colonización española”, La Ilustración Española y Americana, Madrid.

, 16 de junio de 1884, "Los partidos antillanos. ¿Conviene a Cuba la autonomía?”, El Progreso, Madrid.

,24, 25 y 27 de junio de 1884, “El debate sobre Cuba”, El Progreso, Madrid.

, 9, 11 y 22 de julio de 1884, “Anti-autonomía”, El Progreso, Madrid.

Madrid.

, 20 y 21 de agosto de 1884, "Ratificaciones", El Progreso, Madrid.

1 y 2 de septiembre de 1884, "Mi resumen”, El Progreso,

, 14, 15 y 16 de octubre de 1884, "Causas de la ruina de Cuba I-III. El decreto sobre los azúcares”, El Progreso, Madrid.

, 20 de octubre de 1884, "Causas de la ruina de Cuba IV. El azúcar de caña y el de remolacha”, El Progreso, Madrid.

, 21 de octubre de 1884, "Causas de la ruina de Cuba V. El trabajo gratuito y el retribuido”, El Progreso, Madrid.

, 22 de octubre de 1884, "Causas de la ruina de Cuba VI. La crisis económica y administrativa”, El Progreso, Madrid.

, 23 de octubre de 1884, "Causas de la ruina de Cuba. Conclusión”, El Progreso, Madrid.

, 1885, Ensayos sobre politica colonial, Madrid, Imprenta de Miguel Ginesta.

, 16 de febrero de 1885, "El General Fajardo y los autonomistas de Cuba", El Progreso, Madrid. 
, 10 de marzo de 1885, "La política colonial de Inglaterra y la federación del Imperio Británico", Revista de España, Madrid.

, 7, 8 y 11 de junio de 1885, "La raza negra en los pueblos civilizados", Gaceta Universal, Madrid.

, 21, 22, 24 y 25 de junio de 1885, "La tradición colonial española", Gaceta Universal, Madrid.

, 16 y 17 de julio de 1885, "La unidad política entre todas las provincias españolas ultramarinas y peninsulares", Gaceta Universal, Madrid.

, 20 de julio de 1885, "La unidad entre Cuba y la Península”, Gaceta Universal, Madrid.

, 4 de junio de 1886, "La raza negra”, La Opinión, Madrid.

, 15 de junio de 1886, "La república negra", La Opinión, Madrid.

, 1887, La cuestión de Cuba. Madrid, Imprenta de los Hijos de J. A. García.

, 1892, Comercio de España con las Repúblicas HispanoAmericanas, Madrid, Librería Gutenberg (Tipografía FrancoEspañola).

, 13 de febrero de 1892, "El impuesto sobre el azúcar", El Liberal, Madrid.

, 25 de febrero de 1892, "El convenio con los Estados Unidos", El Liberal, Madrid.

, 26 de marzo de 1892, "Intereses castellanos y cubanos (las harinas)", El Liberal, Madrid.

, 3 de mayo de 1892, "Los azúcares peninsulares y los de Ultramar", El Liberal, Madrid.

, 30 de noviembre de 1892, "La circulación monetaria", $\mathrm{La}$ Ilustración Española y Americana, Madrid. 
, 15 de febrero de 1894, "Transacciones necesarias, transacciones temerarias", El Nuevo Mundo, Madrid.

, 15 de febrero de 1894, "Boletín comercial. Azúcares peninsulares", El Nuevo Mundo, Madrid.

, 18 de octubre de 1894 ,"El mal nacional y las reformas de Cuba”, El Nuevo Mundo, Madrid.

14 de marzo de 1895, "Insurrección de Cuba", Nuevo Mundo, Madrid.

,21 de marzo de 1895, "La política en Cuba", Nuevo Mundo, Madrid.

, 2, 16 y 23 de mayo de 1895, "Catalanes y cubanos", Nuevo Mundo, Madrid.

, 25 de julio de 1895, "Política lamentable", Nuevo Mundo, Madrid.

, 3 de octubre de 1895, "Incurables", Nuevo Mundo, Madrid.

, 24 de octubre de 1895, "Nuestra mejor aliada", Nuevo Mundo, Madrid. drid.

, 31 de octubre de 1895, "El dilema”, Nuevo Mundo, Ma-

, 22 de octubre de 1895, "Los comisionados de Puerto Rico", Nuevo Mundo, Madrid.

, 1897, La colonizzazione spagnuola, Torino, Biblioteca si Scienze Politische Amministrative, Seconda Seria, vol. 9.

Revilla Moreno, Manuel de la, noviembre-diciembre de 1875, "El neo-kantismo en España. Ensayos sobre el movimiento intelectual en Alemania, por Don José del Perojo", Revista de España, Madrid. 
Spencer, Herbert, 1879, Obras filosóficas de Spencer. Los primeros principios, José Antonio Irueste (trad.), Madrid, Editorial Perojo (Filósofos Modernos). 
